\title{
Cholecystitis with Spontaneous Cholecysto-Cutaneous Fistula
}

\section{Merdrignac A, Cusumano C and Sulpice L*}

Department of Hepatobiliary and Digestive Surgery, Service de chirurgie hépatobiliaire et Digestive, CHU Pontchaillou, Rennes, France

*Corresponding author: Laurent Sulpice, Department of Hepatobiliary and Digestive Surgery, Service de chirurgie hépatobiliaire et Digestive, CHU Pontchaillou, 2 rue Henri Le Guilloux, 35033 Rennes, France, Tel: +33 299288498, Fax: +33 299284129; E-mail: laurent.sulpice@churennes.fr

Received: February 12, 2018; Accepted: February 16, 2018; Published: February 18, 2018

Citation: Merdrignac A, Cusumano C, Sulpice L (2018) Cholecystitis with Spontaneous Cholecysto-Cutaneous Fistula. Med Case Rep Vol.4 No. 2:I12.

\section{Clinical Image}

An 87-year old woman presented to the emergency department with an abdominal inflammatory mass in the right flank increasing since 15 days. Physical examination revealed signs of decompensated heart failure associated with hypothermia.

Abdominal ultrasound showed a fluid collection in the right abdominal wall evaluated to $15 \times 13 \times 6 \mathrm{~cm}$ containing air bubbles and a stone. Computed tomography confirmed an abscess in the abdominal wall containing a $3 \mathrm{~cm}$ stone spontaneously evacuated from the gallbladder (Figure 1). The acute heart failure contraindicated general anesthesia.
The abscess and the stone were evacuated with a cutaneous incision regarding the abscess under local anesthesia. Microbiological examination of the pus showed E. coli and $M$. morganii. The patient received an anti-biotherapy with ciprofloxacin for 2 weeks.

Hypothermia and biological inflammatory signs disappeared. Acute cholecystitis could go unnoticed in old patients. They may only have symptoms at an advanced stage with complications due to chronic inflammation.

Spontaneous fistulas between the gallbladder and the duodenum, the colon or the abdominal wall could appear. In those cases, the aim of the surgical treatment is to treat the complication such as occlusion or abscess but not the fistula.
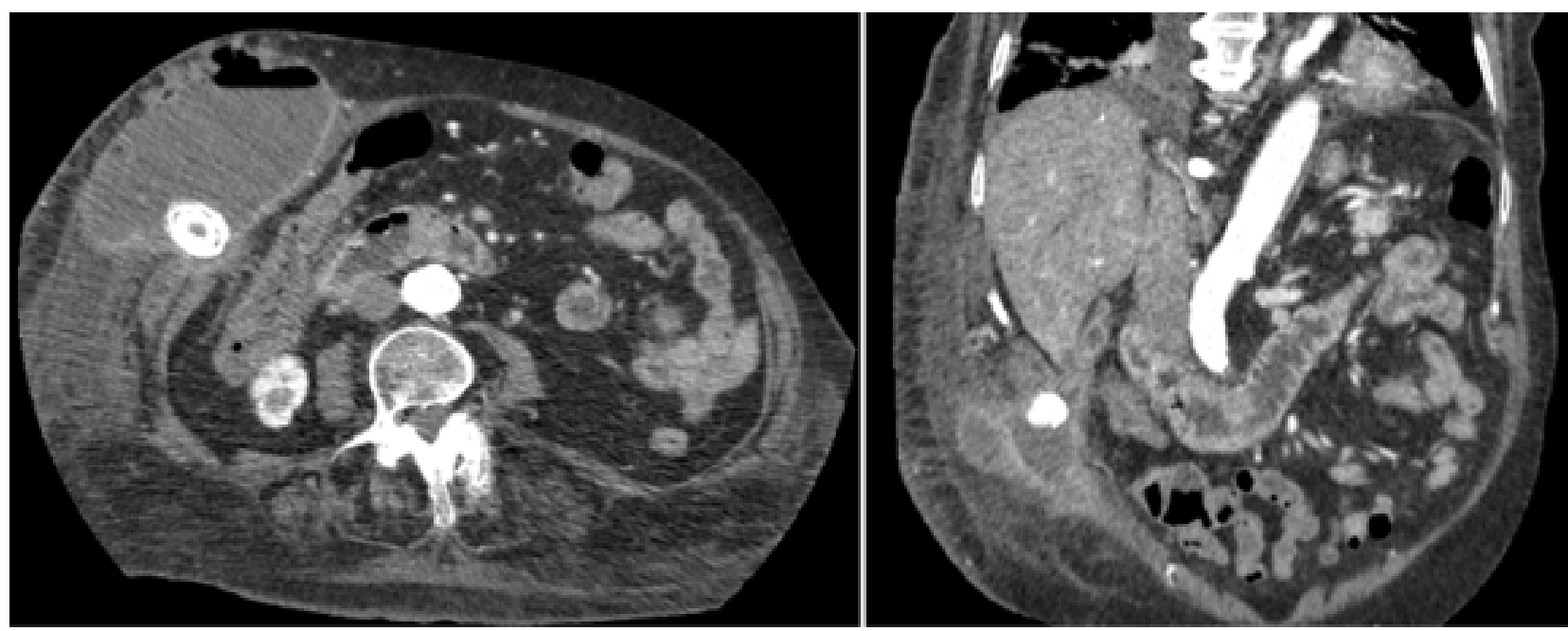

Figure 1 Gallstone migrated from the gall-bladder into an abscess in the anterior abdominal wall. 